\title{
Undernutrition and associated factors among children aged 5-10 years in West Bengal, India: a community-based cross-sectional study
}

\author{
Amitava Pal ${ }^{1,2^{*}} \mathbb{D}$, Sourav Manna ${ }^{3}$, Rishna Dalui ${ }^{2}$, Rupanjan Mukhopadhyay ${ }^{1}$ and Prakash C. Dhara ${ }^{4}$
}

\begin{abstract}
Background: In the previous few decades, India has made significant progress in reducing child mortality and fertility rates; yet, undernutrition remains one of the country's primary public health issues. The goal of this study was to determine the extent of child malnutrition in West Bengal, India, as well as the risk factors linked with it. In diverse districts of West Bengal, a community-based cross-sectional study was undertaken utilizing multi-stage stratified cluster sampling followed by systematic random sampling. Anthropometric, individual, and household characteristics were collected from 2070 children in this study. Height-for-age, weight-for-age, and BMI-for-age z-scores were calculated. The levels and factors related with child undernutrition were studied using univariate and multivariate logistic regression analysis.

Results: Stunting, underweight, and thinness were shown to be prevalent in $25.48 \%, 33 \%$, and $26.88 \%$ of children, respectively. With age, the likelihood of a child becoming malnourished increased. In comparison with girls, boys had a greater chance of being malnourished. Separately, parental educational and occupational statuses were linked to child malnutrition. Undernourished children were more likely to have a mother who was uneducated or undereducated (stunting: $\mathrm{OR}=1.46$; underweight: $\mathrm{OR}=1.49$; thinness: $\mathrm{OR}=1.49$ ). Children from economically disadvantaged families were more likely to be malnourished. Children from households with untreated drinking water and poor sanitation were more likely to be malnourished.
\end{abstract}

Conclusions: The current study showed that there are several risk variables linked to child malnutrition. Undernutrition was caused by illiteracy, filthy drinking water, and poor sanitation, all of which were independent risk factors.

Keyword: Children, Undernutrition, Stunting, Thinness, Socio-demographic factor

\section{Background}

Undernutrition is a state of poor health caused by a lack of nutrients in the body. It is still regarded as one of the most serious public health issues in developing countries, particularly in Southeast Asia and Sub-Saharan Africa [1]. It is one of the most common causes of morbidity and mortality among children all around the world [2]. Every year, more than 10 million children die from diseases that

\footnotetext{
*Correspondence: amitavaergo@gmail.com

${ }^{1}$ Department of Physiology, City College, 102/1, Raja Rammohan Sarani,

Kolkata, West Bengal 700009, India

Full list of author information is available at the end of the article
}

are preventable and treatable. Undernutrition is responsible for at least half of these deaths [3]. If no treatments are implemented, close to one billion children will be cognitively and physically handicapped by 2020 , according to the Global Monitoring Report [4] and Levels and Trends in Child Mortality Report [5]. According to the fourth assessment on the global nutrition situation, the worldwide extent of undernutrition remains unacceptable, and progress toward reducing it is gradual [6].

Because school age is a period of rapid physical and mental development, persistent malnutrition during this time stunts their development [7]. There is a growing understanding that childhood malnutrition is a big 
issue since its consequences are long-lasting and extend beyond infancy. It has both immediate and long-term consequences [8]. Chronic malnutrition is linked to delayed motor and cognitive development, a lower IQ, poor social skills, a delay in physical growth, susceptibility to infectious infections, and major health problems later in life $[3,9,10]$. Long-term malnutrition has been linked to negative repercussions in adulthood, including stunted physical growth, reduced work capacity, poor reproductive outcomes, and an increased risk of chronic diseases [11].

The reasons for undernutrition in children are varied and complex. Undernutrition in children is caused by complex interactions between a variety of factors such as genetic endowments, nutritional status, sociodemographic, reproductive, physical environment, and regional factors $[3,8,10,12-17]$.

One of India's primary human development issues continues to be undernutrition. Despite the fact that India has made significant progress in the last few decades in terms of reducing child mortality and fertility rates, undernutrition among children continues to take many lives. Since 1992, many national health surveys in India have been conducted to offer information on health indicators at subnational levels, including the National Family Health Survey (NFHS), District Level Household Survey, and Annual Health Survey. These national health surveys on undernutrition, on the other hand, are mainly limited to children under the age of five. The fourth in a series of nationwide surveys, the NFHS-4, found that malnutrition is still widespread in India, with the number of malnourished children under the age of five in West Bengal exceeding that of a decade before (stunting 33\%, wasting $20 \%$, and underweight- $32 \%$ respectively) [18]. While the condition in younger children is well-known, the situation in older children is less well-known. In India, the health information system has not kept pace with the epidemiological shift [19]. As a result, evaluating the magnitude of undernutrition and identifying risk factors for it has the potential to play a key role in developing developmental strategies to improve the nutritional condition of children in this state. The goal of the study was to determine the prevalence of stunting, underweight, and thinness in children aged 5 to 10 years in West Bengal, India, as well as their associated factors.

\section{Methods}

\section{Study design and study area}

From September 2017 to March 2018, a communitybased cross-sectional study was done in various districts of West Bengal employing multi-stage stratified cluster sampling followed by systematic random sampling methodology.

\section{Sample size and sampling technique}

The required sample size was calculated using a single population proportion with the following assumption: $38.7 \%$ prevalence of underweight [20], 95\% confidence interval, and 3\% marginal error. A design effect of 2 was utilized because a multi-stage sampling procedure was used to choose participants. Exclusion was given 10\% of the total, while non-responses were given $10 \%$ of the total. As a result, the study requires 2430 (rounded to 2500) volunteers.

In the present study, the participants were selected from six districts (Howrah, Purba Medinipur, Paschim Medinipur, Jargram, Bankura, Purulia) of West Bengal. From each district, five blocks were chosen at random, followed by the selection of six clusters (four villages and two words from town/municipality, roughly whenever possible) from each block. Then, using a systematic random sampling procedure, fifteen participants per cluster were identified. The sampling interval was calculated by dividing the total number of families with children aged 5-10 years in the cluster by the needed number of subjects (fifteen). The first household was chosen at random using the lottery method, and subsequent houses were identified by adding the sampling interval to the random number.

The participants were interviewed and measured in their homes on the same day, as agreed upon by setting up prior appointments. A second visit was performed when mother-child couples were not present at the time of data collection. When that did not work, the nearby family was considered. The younger kid was included in the study for homes with more than one child (aged 5-10 years) to close the time gap for comparing the nutritional state of children in study areas. The study included children who had spent at least $80 \%$ of their lives in the study area since birth. Participants with a history of acute or chronic disorders were not allowed to participate in the study. Because they did not meet these criteria, the authors rejected $153(6.12 \%)$ individuals. A total of 239 people out of 2347 who were eligible declined to participate in the study, and 34 were eliminated owing to missing or incomplete data. As a result, 2074 children (88.37\% of those who were eligible) took part in the study. Outliers were defined as participants with height-for-age $z$-scores (HAZ) of -6 or $>+6$. Four outliers (participants) were excluded from the dataset.

Before beginning the data collection, the study team (supervisors, research team, and field examiners) paid a brief visit to the study areas to meet local community leaders and heads of families and to inform them on the study's goal, data collection processes, etc. During visits to the homes of those who agreed to participate in the study, written informed consent was collected from the 
guardians (left thumb impression for illiterate guardians in the presence of two literate witnesses). The Vidyasagar University Ethics Review Committee provided ethical approval and permission prior to the start of this investigation. This study was performed in accordance with the ethical standards of the committee and with the Helsinki Declaration.

\section{Study variables}

The study's key outcome variable was the nutritional status of the children. Socio-demographic variables (age of the child, child sex, residence, religion, caste, family size, parental education and occupation, economic situation, and household socio-economic status) and environmental health conditions (water supply, availability of latrine, and housing conditions) were the independent variables.

The participants' socio-demographic factors and environmental health conditions were studied using a semistructured questionnaire created after examining related research. The survey questionnaire was prepared in English first and then translated into Bengali. The Bengali version was then translated into English once more. The modified Kuppuswami scale was used to assess the socio-economic status of the individuals [21]. Prior to data collection, the questionnaire was pretested on 50 respondents who were not part of the main study.

Participants' height and weight were measured using a recognized procedure and appropriate landmarks. An anthropometer (Hindustan Minerals) was used to measure height to the nearest $0.1 \mathrm{~cm}$, and a portable weighing machine (Libra) was used to measure weight to the nearest $0.1 \mathrm{~kg}$. A total of two measurements were taken on each subject. When two initial height measurements did not meet the $0.4 \mathrm{~cm}$ requirement, two more measurements were performed, with the mean of the closest records chosen as the best estimate. During the measurements, all individuals wore light clothing and were barefooted. The body mass index (BMI) was calculated using the subjects' height and weight measurements. Participants' ages were taken from their birth certificates.

For data collection, thirty field examiners (15 males and 15 females) with a Bachelor of Science in Human Physiology and fluency in the local language (Bengali) were recruited. All of the examiners went through two training programs, where they learned about the protocol, anthropometry procedures, and interviewing techniques. The instruments were verified for correctness against a standard on a regular basis. The principal investigators used to go to the field to double-check field examiners' interviews and anthropometric measurements. Every questionnaire was double-checked for accuracy and logical consistency. A conference was held between the supervisors, research team, and field examiners at the end of each cluster data collection to discuss practical problems and main concerns.

\section{Statistical analysis}

Stunting, defined as height-for-age $z$-score (HAZ) $<-2$; underweight, defined as weight-for-age $z$-score (WAZ) $<$ -2 ; and thinness, defined as BMI-for-age $z$-score (BAZ) $<-2$, were the study's key outcome variables. Height, weight, and $B M I$ values were converted into $z$-scores of the indices HAZ, WAZ, and BAZ using the WHO Anthro software, version 3.2.2. To summarize the data, categorical variables were summarized using frequency and percentage, while continuous variables were summarized using mean and standard deviation. For continuous and categorical data, Student's $t$-test and chi-square test were used to analyze the differences. One-way ANOVA was employed to assess the age variation of height, weight, and BMI. The levels and factors related with child undernutrition were studied using univariate and multivariate logistic regression analysis. The Statistical Package for Social Sciences was used to conduct all of the analyses (version 20). A statistically significant $p$ value of 0.05 was used.

\section{Results}

There were a total of 2070 children in this study, with 1049 (50.68\%) of them being female. The children's average age was 93.57 months. Approximately $83 \%$ of participants were Hindu, whereas $17 \%$ were Muslim. The majority of the participants (81.5\%) lived in rural areas, while $383(18.5 \%)$ lived in urban areas. The rates of illiteracy among fathers and mothers were found to be $21 \%$ and $31 \%$, respectively. The fathers' occupations were varied. About $85 \%$ of the women were housewives. A large proportion of the households (63.82\%) lacked access to water and relied on public tube-well water for consumption. Thirteen percent of the homes did not have access to a latrine. Each household had an average family size of 5.47 people. The average monthly income per capita was around Rs. 1619.56/US\$ 24.25. Around 63\% of the participants came from families with a monthly per capita income of less than Rs. 2000, whereas $14.78 \%$ came from families with a monthly per capita income of more than Rs. 4000 . Approximately $61 \%$ of those polled belonged to the lower socio-economic class.

The participants' average height, weight, and BMI were $120.18 \pm 10.18 \mathrm{~cm}, 21.89 \pm 6.37 \mathrm{~kg}$, and $14.97 \pm 3.09 \mathrm{~kg} /$ $\mathrm{m}^{2}$, respectively (Table 1). The age- and sex-specific mean height, weight, and BMI were all below the median reference values of WHO [22] (Fig. 1).

Stunting, underweight, and thinness were shown to be prevalent in $25.51 \%, 32.99 \%$, and $26.91 \%$ of children, respectively. Severe stunting, underweight, and thinness 
Table 1 Mean \pm SD of physical characteristics of the participants $(n=2070)$

\begin{tabular}{|c|c|c|c|c|c|c|c|c|}
\hline & Age, years & Number & Height & & Weight & & BMI & \\
\hline & & & Mean $\pm S D$ & $95 \% \mathrm{Cl}$ & Mean $\pm S D$ & $95 \% \mathrm{Cl}$ & Mean $\pm S D$ & $95 \% \mathrm{Cl}$ \\
\hline \multirow[t]{8}{*}{ Boy } & 5 & 160 & $111.2 \pm 9.89$ & $109.66-112.74$ & $18.56 \pm 6.36$ & $17.57-19.56$ & $14.99 \pm 4.74$ & $14.25-15.73$ \\
\hline & 6 & 166 & $115.54 \pm 8.27$ & $114.27-116.81$ & $19.55 \pm 5.77$ & $18.66-20.43$ & $14.48 \pm 3.16$ & $13.99-14.96$ \\
\hline & 7 & 177 & $118.88 \pm 6.79$ & 117.87-119.89 & $21.04 \pm 4.09$ & $20.43-21.65$ & $14.83 \pm 2.14$ & $14.51-15.15$ \\
\hline & 8 & 212 & $123.19 \pm 8.3$ & $122.07-124.32$ & $23.17 \pm 5.47$ & $22.43-23.91$ & $15.14 \pm 2.45$ & $14.81-15.67$ \\
\hline & 9 & 169 & $124.88 \pm 9.52$ & $123.43-126.33$ & $24.95 \pm 6.5$ & 23.96-25.94 & $15.86 \pm 3.07$ & 15.39-13.32 \\
\hline & 10 & 137 & $128.57 \pm 8.38$ & $127.15-129.98$ & $26.44 \pm 7.45$ & $25.18-27.7$ & $15.81 \pm 3.23$ & $15.26-16.35$ \\
\hline & All & 1021 & $120.32 \pm 10.22$ & 119.69-120.95 & $22.22 \pm 6.52$ & $21.82-22.62$ & $15.16 \pm 3.22$ & $14.96-15.36$ \\
\hline & F ratio & & $87.393(p<0.001)$ & & $42.143(p<0.001)$ & & $4.724(p<0.001)$ & \\
\hline \multirow[t]{8}{*}{ Girl } & 5 & 174 & $109.99 \pm 7.74$ & 108.93-111.14 & $16.98 \pm 4.68$ & $16.27-17.68$ & $13.96 \pm 3.19$ & $13.49-14.44$ \\
\hline & 6 & 180 & $113.83 \pm 7.61$ & $112.71-114.95$ & $18.58 \pm 4.22$ & $17.96-19.19$ & $14.29 \pm 2.72$ & 13.89-14.69 \\
\hline & 7 & 191 & $118.9 \pm 7.59$ & 117.82-119.98 & $20.69 \pm 4.29$ & $20.07-21.29$ & $14.58 \pm 2.36$ & $14.24-14.91$ \\
\hline & 8 & 204 & $122.92 \pm 7.64$ & $121.73-122$ & $22.5 \pm 5.07$ & $21.8-23.2$ & $14.8 \pm 2.44$ & $14.46-15.13$ \\
\hline & 9 & 165 & $126.34 \pm 7.9$ & $125.13-127.56$ & $25.09 \pm 7.17$ & $23.98-26.19$ & $15.54 \pm 3.41$ & $15.01-16.06$ \\
\hline & 10 & 135 & $130.85 \pm 6.41$ & $129.76-131.94$ & $27.03 \pm 5.9$ & $26.02-26.8$ & $15.77 \pm 3.26$ & $15.21-16.32$ \\
\hline & All & 1049 & $120.04 \pm 10.15$ & 119.43-120.66 & $21.57 \pm 6.21$ & $21.19-21.94$ & $14.77 \pm 2.94$ & $14.59-14.95$ \\
\hline & F ratio & & $171.794(p<0.001)$ & & $83.987(p<0.001)$ & & $9.114(p<0.001)$ & \\
\hline \multirow[t]{8}{*}{ Both sexes } & 5 & 334 & $110.57 \pm 8.84$ & $109.62-111.52$ & $17.74 \pm 5.59$ & $17.13-18.34$ & $14.46 \pm 4.04$ & $14.02-14.89$ \\
\hline & 6 & 346 & $114.65 \pm 7.96$ & $113.81-115.49$ & $19.04 \pm 5.04$ & $18.51-19.58$ & $14.38 \pm 2.94$ & $14.08-14.69$ \\
\hline & 7 & 368 & $118.89 \pm 7.21$ & $118.15-119.63$ & $20.86 \pm 4.2$ & $20.43-21.29$ & $14.7 \pm 2.27$ & $14.46-14.93$ \\
\hline & 8 & 416 & $123.06 \pm 7.98$ & $122.29-123.83$ & $22.84 \pm 5.29$ & $22.33-23.35$ & $14.97 \pm 2.45$ & $14.73-15.21$ \\
\hline & 9 & 334 & $125.6 \pm 8.79$ & $124.66-126.55$ & $25.02 \pm 6.84$ & $24.28-25.75$ & $15.7 \pm 3.25$ & $15.35-16.05$ \\
\hline & 10 & 272 & $129.7 \pm 7.54$ & $128.8-130.6$ & $26.72 \pm 6.73$ & $25.93-27.53$ & $15.78 \pm 3.25$ & $15.4-16.17$ \\
\hline & All & 2070 & $120.18 \pm 10.18$ & $119.74-120.62$ & $21.89 \pm 6.37$ & $21.62-22.17$ & $14.97 \pm 3.09$ & $14.83-15.1$ \\
\hline & $F$ ratio & & $245.241(p<0.001)$ & & $119.895(p<0.001)$ & & $12.622(p<0.001)$ & \\
\hline
\end{tabular}

were found to be prevalent in $7.1 \%, 13.04 \%$, and $12.42 \%$ of the population, respectively. Approximately $7 \%$ of the participants were overweight or obese. The prevalence of stunting was studied across three BMI groups (thinness, normal, and overweight-obese), and it was discovered that $26 \%$ of thin children and $16 \%$ of normal children were stunted. Around $17 \%$ of children in the overweightobese group were also stunted (Table 2).

\section{Determinants of undernutrition}

Bivariate and multivariate logistic regression analyses were used to evaluate the factors related with undernutrition. Stunting, underweight, and thinness were all studied separately. Stunting was found to be substantially linked with child age, residence, maternal education and occupation, per capita monthly income, family size, type of house, socio-economic position, and household water source in a bivariate study (Table 3 ). The final multivariate logistic regression analysis revealed that stunting was significantly associated with the advanced age of children (8-10 years), lower per capita monthly income (Rs. 2000) (AOR 1.77; 95\% CI 1.17-2.69), and households that used public tube-well water for consumption (AOR 1.33;
95\% CI 1.05-1.69). When compared to children whose mothers were housewives, children whose mothers were laborers or cultivators had a higher risk of stunting (AOR 1.67; 95\% CI 1.192.34). Children from families with fewer than four members were more likely to be stunted (AOR 1.68; 95\% CI 1.08-2.64). Similarly, children from poorer socio-economic homes were found to have a higher risk of stunting.

The frequency of underweight was higher among boys in the bivariate analysis. Underweight was also linked to child age, residence, parental education and occupation, religion, caste, per capita monthly income, type of house, toilet availability, socio-economic level, and household water source (Table 4). The results of the multivariate analysis revealed that males were substantially more likely than girls to be underweight (AOR 1.32, 95\% CI 1.09-1.6). Children's advanced age was connected with a higher risk of being underweight. When comparing children from rural areas to those from urban areas, the probability of being underweight was 1.33 times higher. Children whose fathers worked as laborers (AOR 1.44; 95\% CI 1-2.08) and cultivators (AOR 1.68; 95\% CI 1.19-2.37) had a higher risk of being underweight than 

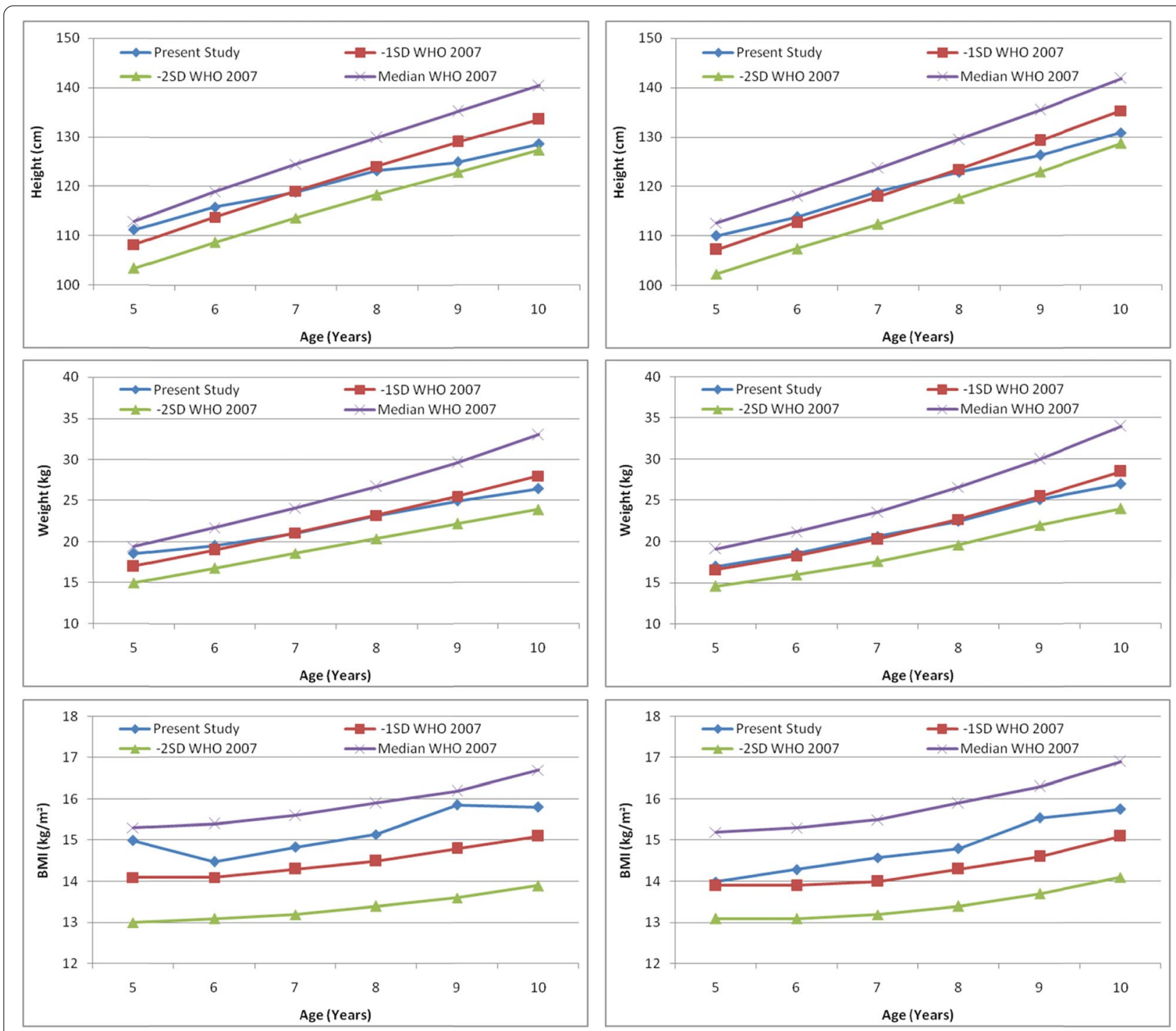

Boy

Girl

Fig. 1 Comparison of mean height, weight and BMI of the present study with WHO reference values

children whose fathers worked in service or ran a business. Children whose mothers were laborers or cultivators had 1.55 times higher risk of being underweight than children whose mothers were housewives. Similarly, children whose mothers were illiterate or only able to sign had a higher risk of being underweight (AOR 1.62; 95\% CI 1.14-2.12), followed by children whose mothers had only primary education (AOR 1.59; 95\% CI 0.95-2.65) compared to those whose mothers had secondary education. Muslim children were found to be more likely than Hindu children to be underweight (AOR 1.35; 95\% CI 1.06-1.71). Children from households without access to a latrine had 1.53 times higher risk of being underweight.
Underweight was related with a lower socio-economic position (AOR 1.42; 95\% CI 0.98-2.02).

The bivariate analysis revealed that child age, residence, religion, parental education and occupation, per capita monthly income, socio-economic position, housing type, and latrine availability were all linked with thinness (Table 5). After correcting for socio-demographic and household factors in a multivariate model, older children were found to have a lower risk of being thin. When compared to children whose fathers ran a business or were in service, children whose fathers were laborers (AOR 2.64; 95\% CI 1.74-3.98) and cultivators (AOR 2.41; 95\% CI 1.64-3.56) had higher probabilities of being thin. 
Table 2 Nutritional status classification of the participants according to gender, BMI-for-age (z-score), and height-for-age (z-score)

\begin{tabular}{|c|c|c|c|c|c|c|c|c|c|c|}
\hline \multicolumn{2}{|c|}{ Height for age } & \multicolumn{9}{|l|}{ BMI-for-age } \\
\hline & & \multicolumn{3}{|l|}{$\leq-2 S D$} & \multicolumn{3}{|c|}{$>-2 S D$ to $<+2 S D$} & \multicolumn{3}{|l|}{$\geq-2 S D$} \\
\hline & & Classification & $n$ & $\%$ & Classification & $n$ & $\%$ & Classification & $n$ & $\%$ \\
\hline \multirow[t]{4}{*}{ Boys } & $\leq-2 \mathrm{SD}$ & U.W. + S. & 70 & 24.73 & S. & 65 & 9.88 & O.W. + S. & 16 & 20 \\
\hline & & & & & U.W. + S. & 116 & 17.63 & & & \\
\hline & $>-2 S D$ & U.W. & 143 & 50.53 & U.W. & 35 & 5.32 & O.W. & 64 & 80 \\
\hline & & $\mathrm{T}$. & 70 & 24.73 & $\mathrm{~N}$ & 442 & 67.17 & & & \\
\hline \multirow[t]{4}{*}{ Girls } & $\leq-2 \mathrm{SD}$ & U.W. + S. & 76 & 27.74 & S. & 76 & 10.58 & O.W. + S. & 7 & 12.28 \\
\hline & & & & & U.W. + S. & 102 & 14.21 & & & \\
\hline & $>-2 \mathrm{SD}$ & U.W. & 115 & 41.97 & U.W. & 25 & 3.48 & O.W. & 50 & 87.72 \\
\hline & & $\mathrm{T}$ & 83 & 30.29 & $\mathrm{~N}$ & 515 & 71.73 & & & \\
\hline \multirow[t]{4}{*}{ All } & $\leq-2 \mathrm{SD}$ & U.W. + S. & 146 & 26.21 & S. & 141 & 10.25 & O.W. + S. & 23 & 16.79 \\
\hline & & & & & U.W. + S. & 218 & 15.84 & & & \\
\hline & $>-2 \mathrm{SD}$ & U.W. & 258 & 46.32 & U.W. & 60 & 4.36 & O.W. & 114 & 83.21 \\
\hline & & $\mathrm{T}$. & 153 & 27.47 & $\mathrm{~N}$ & 957 & 69.55 & & & \\
\hline
\end{tabular}

U.W underweight, $S$ stunting, $T$ thin, $N$ normal, $O . W$ overweight

In terms of mother's occupation, children whose mothers worked as a laborer or a cultivator were more likely to be thin (AOR 1.62; 95\% CI 1.18-2.22) than children whose mothers worked as housewives. Children whose mothers were illiterate or had low educational levels had a muchincreased risk of being thin. Children from families without access to a latrine were more likely to be thin. When compared to children from upper socio-economic households, the likelihood of being thin was higher among children from lower socio-economic families (AOR 1.68; 95\% CI 1.12-2.39), followed by children from middle socioeconomic families (AOR 1.2; 95\% CI 0.64-2.27).

\section{Discussion}

Despite significant economic improvement over the last two to three decades and an overarching goal of addressing health needs through a variety of comprehensive programs, India's health outcomes have been less outstanding. Stunting, underweight, and thinness were shown to be prevalent in $25.51 \%, 32.99 \%$, and $26.91 \%$ of the children in this study, respectively. The prevalence of stunting among the children investigated was moderate, but the prevalence of underweight was very high, according to the WHO scale of severity malnutrition [23]. Various research, both in India and overseas, have shown similar outcomes. When compared to a communitybased cross-sectional research conducted in West Bengal, where $26.5 \%$ of children were stunted and $38.7 \%$ were underweight, this study demonstrated a lower prevalence of stunting and underweight [20]. In Orissa, India's south-eastern state, the prevalence of underweight, stunting, and thinness was $24.61 \%, 39.51 \%$, and $48.35 \%$, respectively [24]. In comparison with global estimates, the prevalence of stunting among children in this study was lower than that reported in Bangladesh (60\%) [17], Ethiopia (39.8\%) [13], and Egypt (53.2\%) [15] but greater than that in Brazil (15.5\%) [12].

The likelihood of a child being undernourished increased with age, according to one study. In terms of stunting and thinness, the age gap was significant. The increased frequency of parasite infection seen with increasing age may be linked to the higher prevalence of undernutrition among older children [12]. Similarly, many studies in India and elsewhere have found that older children are more prone than younger children to become malnourished [3, 12, 13, 25]. In comparison with girls, boys had a greater chance of being malnourished. Male children were also shown to be more likely than female children to be undernourished, according to several studies $[8,15]$. The cause of the gender gap in undernutrition is unknown; however, some studies have found that boys are more influenced by environmental stress while playing, such as frequent illnesses and exposure to toxins and air pollution, than girls $[8,15]$.

The literature on the causes of malnutrition is extensive. Low diet, poor socio-economic conditions, environmental, socio-demographic inequality, and ethnicity are the main causes of undernutrition in developing countries [10, 12, 26, 27]. According to Maia et al., socio-economic, cultural, and environmental factors that interfere with nutrient intake have a greater impact on malnutrition [12].

Parental educational and occupational statuses were found to be independently linked with children's 
Table 3 Factors associated with stunting among children aged 5-10 years

\begin{tabular}{|c|c|c|c|c|c|c|c|}
\hline \multirow[t]{2}{*}{ Variables } & & \multicolumn{6}{|c|}{ Stunting } \\
\hline & & $\%$ & $x^{2}$ ( $p$ value) & COR $(95 \% \mathrm{Cl})$ & $p$ value & AOR $(95 \% \mathrm{Cl})$ & $p$ value \\
\hline \multirow[t]{2}{*}{ Sex } & Male & 26.15 & $0.439(0.508)$ & $1.07(0.88-1.3)$ & 0.508 & $1.09(0.89-1.34)$ & 0.402 \\
\hline & Female & 24.88 & & Reference & & - & \\
\hline \multirow[t]{6}{*}{ Age } & 5 & 20.06 & $44.117(0.000)$ & Reference & & - & \\
\hline & 6 & 17.05 & & $0.82(0.56-1.21)$ & 0.313 & $0.83(0.56-1.23)$ & 0.351 \\
\hline & 7 & 22.28 & & $1.14(0.79-1.63)$ & 0.472 & $1.21(0.8-1.77)$ & 0.319 \\
\hline & 8 & 27.4 & & $1.5(1.07-2.12)$ & 0.02 & $1.71(1.19-2.45)$ & 0.004 \\
\hline & 9 & 33.83 & & $2.04(1.43-2.89)$ & 0.000 & $2.39(1.65-3.45)$ & 0.000 \\
\hline & 10 & 34.19 & & $2.07(1.43-2.99)$ & 0.000 & $2.26(1.55-3.3)$ & 0.000 \\
\hline \multirow[t]{2}{*}{ Residence } & Rural & 26.44 & $4.278(0.039)$ & $1.32(1.01-1.72)$ & 0.042 & $1.24(0.94-1.64)$ & 0.126 \\
\hline & Urban & 21.41 & & Reference & & - & \\
\hline \multirow[t]{2}{*}{ Religion } & Hindu & 24.91 & $1.845(0.174)$ & Reference & & - & \\
\hline & Muslim & 28.41 & & $1.2(0.93-1.54)$ & 0.171 & $1.18(0.89-1.55)$ & 0.24 \\
\hline \multirow[t]{2}{*}{ Cast } & Lower (SC and ST) & 29.4 & $3.43(0.064)$ & $1.27(0.99-1.63)$ & 0.061 & $1.15(0.88-1.52)$ & 0.301 \\
\hline & Other & 24.68 & & Reference & & - & \\
\hline \multirow[t]{3}{*}{ Occupational status of the father } & Laborer & 28.55 & $5.745(0.057)$ & $1.34(1.05-1.69)$ & 0.018 & $1.07(0.78-1.46)$ & 0.686 \\
\hline & Cultivator & 26.07 & & $1.18(0.93-1.49)$ & 0.175 & $1.08(0.8-1.45)$ & 0.609 \\
\hline & Business/service & 23.01 & & Reference & & - & \\
\hline \multirow[t]{4}{*}{ Educational status of the father } & Illiterate or just able to sign & 26.02 & $2.99(0.393)$ & $1.24(0.89-1.73)$ & 0.198 & $1.17(0.86-1.64)$ & 0.029 \\
\hline & Up to primary & 26.61 & & $1.28(0.96-1.71)$ & 0.092 & $1.07(0.71-1.46)$ & 0.209 \\
\hline & Secondary & 26.04 & & $1.22(0.87-1.7)$ & 0.25 & $1.09(0.6-1.85)$ & 0.606 \\
\hline & Above secondary & 21.05 & & Reference & & - & \\
\hline \multirow[t]{3}{*}{ Occupational status of the mother } & Housewife & 24.91 & $12.983(0.002)$ & Reference & & - & \\
\hline & Laborer/cultivator & 33.77 & & $1.54(1.14-2.06)$ & 0.004 & $1.67(1.19-2.34)$ & 0.003 \\
\hline & Business/service & 15.48 & & $0.55(0.3-1.01)$ & 0.053 & $0.72(0.37-1.41)$ & 0.339 \\
\hline \multirow[t]{4}{*}{ Educational status of the mother } & Illiterate or just able to sign & 28.73 & $11.884(0.008)$ & $2.01(1.31-3.09)$ & 0.001 & $1.46(0.81-2.62)$ & 0.211 \\
\hline & Up to primary & 25.44 & & $1.71(1.12-2.59)$ & 0.013 & $1.43(0.83-2.47)$ & 0.196 \\
\hline & Secondary & 24.18 & & $1.59(1.01-2.54)$ & 0.049 & $1.3(0.85-2.39)$ & 0.173 \\
\hline & Above secondary & 16.67 & & Reference & & - & \\
\hline \multirow[t]{3}{*}{ Economic status } & Rs. $\leq 2000$ & 28.23 & $14.898(0.001)$ & $1.65(1.21-2.24)$ & 0.002 & $1.77(1.17-2.69)$ & 0.007 \\
\hline & Rs. $2001-4000$ & 21.88 & & $1.17(0.82-1.68)$ & 0.386 & $1.22(0.81-1.84)$ & 0.341 \\
\hline & Rs. $>4000$ & 19.28 & & Reference & & - & \\
\hline \multirow[t]{3}{*}{ Family size } & $\leq 4$ & 26.83 & $5.775(0.056)$ & $1.65(1.08-2.52)$ & 0.021 & $1.68(1.08-2.64)$ & 0.022 \\
\hline & $5-8$ & 25.61 & & $1.55(1.02-2.35)$ & 0.041 & $1.51(0.98-2.34)$ & 0.061 \\
\hline & $\geq 9$ & 18.18 & & Reference & & - & \\
\hline \multirow[t]{3}{*}{ Type of house } & Kutcha & 28.76 & $6.843(0.033)$ & $1.35(1.06-1.72)$ & 0.014 & $1.15(0.69-1.29)$ & 0.738 \\
\hline & Semi pucca & 24.33 & & $1.08(0.84-1.39)$ & 0.558 & $1.03(0.61-1.13)$ & 0.228 \\
\hline & Pucca & 22.96 & & Reference & & - & \\
\hline \multirow[t]{2}{*}{ Availability of latrine } & Yes & 24.86 & $2.878(0.09)$ & Reference & & - & \\
\hline & No & 29.71 & & $1.28(0.97-1.69)$ & 0.086 & $1.15(0.81-1.63)$ & 0.442 \\
\hline \multirow[t]{2}{*}{ Water source } & Tube well & 27.78 & $10.116(0.001)$ & $1.4(1.14-1.74)$ & 0.002 & $1.33(1.05-1.69)$ & 0.016 \\
\hline & Deep tube well & 21.50 & & Reference & & - & \\
\hline \multirow[t]{3}{*}{ SES } & Lower & 27.59 & $21.239(0.000)$ & $2.94(1.75-4.94)$ & 0.000 & $2.55(1.19-5.48)$ & 0.016 \\
\hline & Middle & 24.57 & & $2.51(1.47-4.29)$ & 0.001 & $2.36(1.28-4.36)$ & 0.006 \\
\hline & Upper & 11.49 & & Reference & & - & \\
\hline
\end{tabular}


Table 4 Factors associated with underweight among children aged 5-10 years

\begin{tabular}{|c|c|c|c|c|c|c|c|}
\hline \multirow[t]{2}{*}{ Variables } & & \multicolumn{6}{|c|}{ Underweight } \\
\hline & & $\%$ & $x^{2}$ ( $p$ value $)$ & COR $(95 \% \mathrm{Cl})$ & $p$ value & AOR $(95 \% \mathrm{Cl})$ & $p$ value \\
\hline \multirow[t]{2}{*}{ Sex } & Male & 35.75 & $6.916(0.009)$ & $1.28(1.06-1.54)$ & 0.009 & $1.32(1.09-1.6)$ & 0.005 \\
\hline & Female & 30.31 & & Reference & & & \\
\hline \multirow[t]{6}{*}{ Age } & 5 & 29.04 & $9.611(0.087)$ & Reference & & & \\
\hline & 6 & 30.92 & & 1.09 (0.79-1.52) & 0.592 & $1.19(0.85-1.68)$ & 0.31 \\
\hline & 7 & 30.98 & & $1.1(0.79-1.51)$ & 0.576 & $1.31(0.93-1.84)$ & 0.125 \\
\hline & 8 & 33.17 & & $1.21(0.89-1.66)$ & 0.226 & $1.58(1.13-2.21)$ & 0.008 \\
\hline & 9 & 36.23 & & $1.39(1-1.92)$ & 0.048 & $1.73(1.22-2.44)$ & 0.002 \\
\hline & 10 & 38.97 & & $1.56(1.11-2.19)$ & 0.01 & $1.69(1.19-2.4)$ & 0.004 \\
\hline \multirow[t]{2}{*}{ Residence } & Rural & 34.38 & $8.138(0.004)$ & $1.42(1.11-1.82)$ & 0.005 & $1.33(1.03-1.72)$ & 0.031 \\
\hline & Urban & 26.89 & & Reference & & & \\
\hline \multirow[t]{2}{*}{ Religion } & Hindu & 31.84 & $5.982(0.014)$ & Reference & & & \\
\hline & Muslim & 38.64 & & $1.35(1.06-1.71)$ & 0.014 & $1.3(1.01-1.68)$ & 0.043 \\
\hline \multirow[t]{2}{*}{ Cast } & Lower (SC and ST) & 37.64 & $4.233(0.04)$ & $1.28(1.1-1.62)$ & 0.038 & $1.1(0.85-1.4)$ & 0.508 \\
\hline & Other & 32 & & Reference & & & \\
\hline \multirow[t]{3}{*}{ Occupational status of the father } & Laborer & 37.95 & $32.318(0.000)$ & $1.74(1.38-2.18)$ & 0.000 & $1.44(1-2.08)$ & 0.049 \\
\hline & Cultivator & 37.84 & & $1.73(1.38-2.16)$ & 0.000 & $1.68(1.19-2.37)$ & 0.003 \\
\hline & Business/service & 26.05 & & Reference & & & \\
\hline \multirow[t]{4}{*}{ Educational status of the father } & Illiterate or just able to sign & 40.48 & $29.464(0.000)$ & $2.33(1.7-3.18)$ & 0.000 & $1.17(0.6-1.56)$ & 0.899 \\
\hline & Up to primary & 33.63 & & $1.73(1.31-2.29)$ & 0.000 & $1.09(0.65-1.5)$ & 0.957 \\
\hline & Secondary & 33.64 & & $1.71(1.23-2.36)$ & 0.001 & $1.23(0.83-1.84)$ & 0.302 \\
\hline & Above secondary & 20.74 & & Reference & & & \\
\hline \multirow[t]{3}{*}{ Occupational status of the mother } & Housewife & 44.74 & $20.956(0.000)$ & Reference & & & \\
\hline & Laborer/cultivator & 20.24 & & $1.71(1.29-2.27)$ & 0.000 & $1.55(1.13-2.12)$ & 0.007 \\
\hline & Business/service & 32.08 & & $0.54(0.3-0.9)$ & 0.025 & $0.84(0.46-1.52)$ & 0.572 \\
\hline \multirow[t]{4}{*}{ Educational status of the mother } & Illiterate or just able to sign & 39.02 & $41.329(0.000)$ & $2.65(1.77-3.96)$ & 0.000 & $1.62(1.14-2.12)$ & 0.032 \\
\hline & Up to primary & 34.73 & & $2.2(1.49-3.27)$ & 0.000 & $1.59(0.95-2.65)$ & 0.08 \\
\hline & Secondary & 23.88 & & $1.3(0.83-2.03)$ & 0.25 & $1.11(0.68-1.83)$ & 0.738 \\
\hline & Above secondary & 19.44 & & Reference & & & \\
\hline \multirow[t]{3}{*}{ Economic status } & Rs. $\leq 2000$ & 37.41 & $33.336(0.000)$ & $1.98(1.48-2.64)$ & 0.000 & $1.33(0.88-2.01)$ & 0.171 \\
\hline & Rs. $2001-4000$ & 26.91 & & $1.22(0.87-1.71)$ & 0.249 & $1.14(0.63-1.49)$ & 0.746 \\
\hline & Rs. $>4000$ & 23.2 & & Reference & & & \\
\hline \multirow[t]{3}{*}{ Family size } & $\leq 4$ & 32.34 & $2.994(0.224)$ & $1.24(0.85-1.79)$ & 0.261 & $1.44(0.97-2.13)$ & 0.07 \\
\hline & $5-8$ & 34.3 & & $1.35(0.94-1.94)$ & 0.105 & $1.39(0.95-2.03)$ & 0.089 \\
\hline & $\geq 9$ & 27.88 & & Reference & & & \\
\hline \multirow[t]{3}{*}{ Type of house } & Kutcha & 38.08 & $22.956(0.000)$ & $1.73(1.38-2.18)$ & 0.000 & $1.05(0.78-1.41)$ & 0.765 \\
\hline & Semi pucca & 33.88 & & $1.44(1.14-1.83)$ & 0.002 & $0.99(0.75-1.33)$ & 0.973 \\
\hline & Pucca & 26.19 & & Reference & & & \\
\hline \multirow[t]{2}{*}{ Availability of latrine } & Yes & 31.05 & $22.123(0.000)$ & Reference & & & \\
\hline & No & 45.65 & & $1.86(1.44-2.41)$ & 0.000 & $1.53(1.11-2.1)$ & 0.01 \\
\hline \multirow[t]{2}{*}{ Water source } & Tube well & 35.28 & $8.682(0.003)$ & $1.34(1.1-1.62)$ & 0.003 & $1.19(0.96-1.48)$ & 0.105 \\
\hline & Deep tube well & 28.97 & & Reference & & & \\
\hline \multirow[t]{3}{*}{ SES } & Lower & 36.71 & $30.118(0.000)$ & $2.72(1.76-4.22)$ & 0.000 & $1.42(0.98-2.02)$ & 0.048 \\
\hline & Middle & 29.11 & & $1.93(1.22-3.04)$ & 0.005 & $1.17(0.68-2.01)$ & 0.575 \\
\hline & Upper & 17.57 & & Reference & & & \\
\hline
\end{tabular}


Table 5 Factors associated with thinness among children aged 5-10 years

\begin{tabular}{|c|c|c|c|c|c|c|c|}
\hline \multirow[t]{2}{*}{ Variables } & & \multicolumn{6}{|c|}{ Thinness } \\
\hline & & $\%$ & $x^{2}$ ( $p$ value $)$ & COR $(95 \% \mathrm{Cl})$ & $p$ value & AOR $(95 \% \mathrm{Cl})$ & $p$ value \\
\hline \multirow[t]{2}{*}{ Sex } & Male & 27.72 & $0.672(0.412)$ & $1.08(0.89-1.32)$ & 0.413 & $1.1(0.9-1.36)$ & 0.346 \\
\hline & Female & 26.12 & & Reference & & & \\
\hline \multirow[t]{6}{*}{ Age } & 5 & 37.13 & $43.472(0.000)$ & Reference & & & \\
\hline & 6 & 31.79 & & $0.78(0.56-1.09)$ & 0.157 & $0.8(0.56-1.13)$ & 0.207 \\
\hline & 7 & 21.47 & & $0.42(0.3-0.6)$ & 0.000 & $0.52(0.36-0.75)$ & 0.000 \\
\hline & 8 & 21.88 & & $0.47(0.34-0.65)$ & 0.000 & $0.61(0.43-0.87)$ & 0.006 \\
\hline & 9 & 20.06 & & $0.46(0.33-0.65)$ & 0.000 & $0.57(0.4-0.81)$ & 0.002 \\
\hline & 10 & 31.62 & & $0.79(0.57-1.08)$ & 0.144 & $0.86(0.62-1.2)$ & 0.382 \\
\hline \multirow[t]{2}{*}{ Residence } & Rural & 27.92 & $4.883(0.027)$ & $1.34(1.03-1.74)$ & 0.03 & $1.22(0.93-1.61)$ & 0.156 \\
\hline & Urban & 22.45 & & Reference & & & \\
\hline \multirow[t]{2}{*}{ Religion } & Hindu & 26.02 & $3.966(0.046)$ & Reference & & & \\
\hline & Muslim & 31.25 & & $1.29(1.01-1.66)$ & 0.044 & $1.17(0.9-1.54)$ & 0.247 \\
\hline \multirow[t]{2}{*}{ Cast } & Lower (SC and ST) & 29.12 & $1.085(0.298)$ & $1.14(0.89-1.47)$ & 0.295 & $0.96(0.73-1.26)$ & 0.777 \\
\hline & Other & 26.44 & & Reference & & & \\
\hline \multirow[t]{3}{*}{ Occupational status of the father } & Laborer & 35.21 & $77.474(0.000)$ & $2.66(2.08-3.41)$ & 0.000 & $2.64(1.74-3.98)$ & 0.000 \\
\hline & Cultivator & 32.75 & & $2.39(1.87-3.05)$ & 0.000 & $2.41(1.64-3.56)$ & 0.000 \\
\hline & Business/service & 16.94 & & Reference & & & \\
\hline \multirow[t]{4}{*}{ Educational status of the father } & Illiterate or just able to sign & 37.59 & $45.649(0.000)$ & $3.08(2.19-4.33)$ & 0.000 & $1.19(0.6-1.64)$ & 0.968 \\
\hline & Up to primary & 26.5 & & $1.84(1.35-2.52)$ & 0.000 & $1.09(0.57-1.41)$ & 0.629 \\
\hline & Secondary & 26.04 & & $1.84(1.28-2.62)$ & 0.001 & $1.22(0.78-1.89)$ & 0.381 \\
\hline & Above secondary & 15.48 & & Reference & & & \\
\hline \multirow[t]{3}{*}{ Occupational status of the mother } & Housewife & 44.3 & $37.73(0.000)$ & Reference & & & \\
\hline & Laborer/cultivator & 19.05 & & $2.38(1.79-3.16)$ & 0.000 & $1.62(1.18-2.22)$ & 0.003 \\
\hline & Business/service & 25.03 & & $0.7(0.4-1.23)$ & 0.217 & $1.33(0.71-2.48)$ & 0.377 \\
\hline \multirow[t]{4}{*}{ Educational status of the mother } & Illiterate or just able to sign & 34.1 & $52.246(0.000)$ & $3.36(2.12-5.32)$ & 0.000 & $1.7(0.98-3.06)$ & 0.044 \\
\hline & Up to primary & 27.88 & & $2.51(1.59-3.95)$ & 0.000 & $1.92(1.07-3.44)$ & 0.029 \\
\hline & Secondary & 17.61 & & $1.39(0.83-2.32)$ & 0.209 & $1.29(0.73-2.28)$ & 0.389 \\
\hline & Above secondary & 13.33 & & Reference & & & \\
\hline \multirow[t]{3}{*}{ Economic status } & Rs. $\leq 2000$ & 31.06 & $35.992(0.000)$ & $2.31(1.67-3.19)$ & 0.000 & $1.27(0.8-2)$ & 0.304 \\
\hline & Rs. $2001-4000$ & 22.1 & & $1.45(0.99-2.11)$ & 0.051 & $0.97(0.62-1.51)$ & 0.878 \\
\hline & Rs. $>4000$ & 16.34 & & Reference & & & \\
\hline \multirow[t]{3}{*}{ Family size } & $\leq 4$ & 24.07 & $5.843(0.054)$ & $0.75(0.52-1.09)$ & 0.128 & $0.91(0.61-1.35)$ & 0.626 \\
\hline & $5-8$ & 28.69 & & $0.95(0.66-1.36)$ & 0.791 & $1.04(0.71-1.53)$ & 0.83 \\
\hline & $\geq 9$ & 29.7 & & Reference & & & \\
\hline \multirow[t]{3}{*}{ Type of house } & Kutcha & 30.09 & $30.617(0.000)$ & $1.82(1.42-2.34)$ & 0.000 & $1(0.72-1.39)$ & 0.996 \\
\hline & Semi pucca & 30.9 & & $1.89(1.47-2.44)$ & 0.000 & $1.11(0.81-1.51)$ & 0.522 \\
\hline & Pucca & 19.11 & & Reference & & & \\
\hline \multirow[t]{2}{*}{ Availability of latrine } & Yes & 24.58 & $34.319(0.000)$ & Reference & & & \\
\hline & No & 42.03 & & $2.22(1.71-2.89)$ & 0.000 & $1.58(1.13-2.19)$ & 0.007 \\
\hline \multirow[t]{2}{*}{ Water source } & Tube well & 27.48 & $0.607(0.436)$ & $1.08(0.89-1.33)$ & 0.437 & $1.07(0.77-1.22)$ & 0.82 \\
\hline & Deep tube well & 25.9 & & Reference & & & \\
\hline \multirow[t]{3}{*}{ SES } & Lower & 31.49 & $46.799(0.000)$ & $3.79(2.23-6.45)$ & 0.000 & $1.68(1.12-2.39)$ & 0.006 \\
\hline & Middle & 21.44 & & $2.25(1.29-3.91)$ & 0.004 & $1.2(0.64-2.27)$ & 0.571 \\
\hline & Upper & 10.81 & & Reference & & & \\
\hline
\end{tabular}


undernutrition in this study. In comparison with children whose mothers worked in other career groups, we discovered that children whose mothers worked in professional jobs had superior nutritional results. When compared to children of better-educated mothers, children of illiterate or less educated mothers were more likely to be undernourished. The recent study also discovered that children whose mothers worked in agriculture had a higher risk of malnutrition. Women working in the agricultural sector in India have lower educational levels and come from impoverished families. Higher educational and occupational status may have an indirect impact on a child's nutritional health by influencing the family's living conditions, child care, knowledge of child-rearing techniques, diet quality, and physical surroundings [13]. Other studies in India [10], Ethiopia [13], Brazil [12], Egypt [15], and Bangladesh [17] found that children from uneducated parents were more likely to be undernourished than children from educated parents. It is claimed that women in professional jobs with higher educational levels are more aware of personal hygiene, have greater access to household resources, and have the ability to make independent decisions that improve children's nutritional status as a result of their exposure to the outside world [10]. Mesfin et al. found that children born to working mothers had a higher risk of malnutrition than children born to housewives [16]. Undernutrition was more common in children from rural regions than in children from urban areas. This was in line with previous research [13, 24]. The disparity could be related to a lack of health knowledge, medical service accessibility, and dietary awareness among rural women. In addition, there are significant disparities in India's healthcare system between rural and urban areas. Children from lower-income families were more likely to be undernourished. According to Tigga et al., the prevalence of child undernutrition was higher in poor families [26]. Lower socio-economic status is linked to poor economic position and low family literacy, which leads to lower purchasing power and food insecurity, all of which contribute to greater rates of undernutrition [28].

In comparison with joint families, children raised in nuclear homes were more likely to be undernourished. In a prior research of teenagers in West Bengal, it was discovered that children raised in nuclear homes were more likely to be undernourished than those raised in united families [10]. Similar findings were also reported by Sapkota and Gurung [29].

Children who drank untreated water had a higher prevalence of undernutrition. Similarly, several studies have found that those who do not have access to clean water are more likely to contract infections and develop chronic diseases, which increases the risk of malnutrition
$[3,14,17]$. In this study, inadequate sanitation was found to be a risk factor for child malnutrition. Poor sanitation can have a negative impact on one's health and nutrition, as well as promote the spread of chronic diseases [30]. Unsanitary conditions and practices, such as unsanitary latrines, excrement on premises, open drainage surrounding or near the house, and drinking unprotected water, can raise the risk of infectious disease, which can lead to malnutrition. The current study did not look at the prevalence of parasite infestations, diarrhea episodes, or other chronic disorders. Our research location is known to be a cholera- and malaria-endemic area, and other particular illnesses, such as chronic parasite infestations linked to malnutrition, were common [31]. Because of the filthy surroundings, it was likely that the rural population was more susceptible to infections. Rural folks wash their dishes and clothes in contaminated pond water, making them more prone to parasitic and chronic diseases, potentially leading to a higher frequency of malnutrition $[8,10,32]$.

\section{Conclusions}

Stunting, underweight, and thinness among children in this community are still a serious public health concern, according to the findings of this study. Multiple risk factors for child malnutrition were discovered in the current investigation. Undernutrition was caused by illiteracy, untreated drinking water, and poor sanitation, all of which were independent risk factors. Stunting was linked to advanced age, poor economy, a nuclear family, drinking untreated water, maternal occupation, and poorer socio-economic level. Male gender, advanced age, rural habitation, mother illiteracy, parental occupation, and toilet availability were all linked to being underweight. Thinness was associated with mother illiteracy, parental profession, poorer socio-economic level, and the availability of a latrine. As a result, access to clean and sufficient drinking water, as well as sanitation and hygiene standards, should be taken into account.

\section{Study limitations}

This study has some drawbacks, despite its efficient sampling design, huge sample size, and robust analysis. Different predictors affecting child nutrition were investigated in this study, but some important confounding variables such as physical activity, parasitic infection, child's history of illness, daily intake, and household food insecurity were overlooked. The use of cross-sectional data has drawbacks, as the cross-sectional nature of the study design makes it impossible to establish proper causal links between predictors and outcome variables. A cohort research, rather than a cross-sectional study, is more appropriate for understanding the potential 
temporal connection of predictors and child undernutrition. Monthly income and socio-demographic characteristics may be subject to desirability bias. As a result, the relationship between the predictors and the outcome variables may be overestimated. However, by paying attention to the parent's occupation, we can lessen this likely prejudice. In addition, we only employed anthropometric indices to assess undernutrition, with no biochemical measures included.

\section{Acknowledgements}

All the authors would like to express their gratitude and thanks to the study participants and data collectors for their great contribution for the completion of this study.

\section{Authors' contributions \\ Conceived and designed the experiments: Amitava Pal and Prakash C. Dhara. Analyzed the data: Amitava Pal, Sourav Manna, Rishna Dalui, and Rupanjan Mukhopadhyay. Wrote the paper: Amitava Pal. Carried out the literature review: Amitava Pal, Sourav Manna, Rishna Dalui, and Rupanjan Mukhopad- hyay. Reviewed and approved the final version of the manuscript: Amitava Pal, Sourav Manna, Rishna Dalui, Rupanjan Mukhopadhyay, and Prakash C. Dhara. The author(s) read and approved the final manuscript.}

\section{Funding}

The study does not have a funding source.

\section{Availability of data and materials}

The datasets used and/or analyzed during the current study are available from the corresponding author on reasonable request.

\section{Declarations}

\section{Ethics approval and consent to participate}

The Vidyasagar University Ethics Review Committee provided ethical approval and permission prior to the start of this investigation (Ethical No.: VU/R/ Ethical/3-(ii)/2012; dated: 22 March 2012). During visits to the homes of those who agreed to participate in the study, written informed consent was collected from the guardians (left thumb impression for illiterate guardians in the presence of two literate witnesses). This study was performed in accordance with the ethical standards of the committee and with the Helsinki Declaration.

\section{Consent for publication}

Not applicable

\section{Competing interests}

The authors declare that they have no competing interests.

\section{Author details}

'Department of Physiology, City College, 102/1, Raja Rammohan Sarani, Kolkata, West Bengal 700009, India. ${ }^{2}$ Department of Physiology, Panskura Banamali College, Panskura, Purba Midnapore, West Bengal, India. ${ }^{3}$ Department of Physiology, National Medical College, Birgunj, Parsa, Nepal. ${ }^{4}$ Department of Human Physiology, Vidyasagar University, Midnapore, West Bengal, India.

Received: 9 September 2021 Accepted: 18 November 2021

Published online: 03 December 2021

\section{References}

1. Stephenson LS, Latham MC, Ottesen EA (2000) Malnutrition and parasitic helminth infections. Parasitology 121(Suppl):S23-S38

2. UNICEF (2005) The State of the World's Children 2005- Childhood under threat. www.unicef.org/sowc05/english/fullreport.html

3. Mengistu K, Alemu K, Destaw B (2013) Prevalence of malnutrition and associated factors among children aged 6-59 months at HidabuAbote district, North Shewa, Oromia regional state. J Nutr Disorders Ther T1:001. https://doi.org/10.4172/2161-0509.T1-001

4. Global Monitoring Report (2012) Food prices, nutrition, and the millennium development goals. http://go.worldbank.org/3LBH3GVIYO.

5. Levels and trends in child mortality report (2011) Estimates developed by the an inter-agency group for child mortality estimation. http://www. childinfo.org/files/Child_Mortality_Report_2011.

6. ACC/SCN (2000) Fourth report on the world nutrition situation. United Nations, Geneva

7. Kuczmarski RJ, Ogden CL, Guo SS et al (2002) CDC growth charts for the United States: methods and development. Vital Health Stat 11:1-190

8. Asfaw M, Wondaferash M, Taha M, Dube L (2015) Prevalence of undernutrition and associated factors among children aged between six to fifty nine months in Bule Hora district, South Ethiopia. BMC Public Health 15:41. https://doi.org/10.1186/s12889-015-1370-9

9. Park K (2005) Park's textbook of preventive and social medicine, 18th edn. BanarasidasBhanot Publishers, Jabalpur, p 405

10. Pal A, Pari AK, Sinha A, Dhara PC (2017) Prevalence of undernutrition and associated factors: a cross-sectional study among rural adolescents in West Bengal, India. IntJPediatAdol Med 4:9-18

11. Singh JP, Gupta SB, Shrotriya VP, Singh PN (2013) Study of nutritional status among under five children attending outpatient department at a primary care rural hospital, Bareilly (UP). Sch J App Med Sci 1:769-773

12. Maia MMM, Fausto MA, Vieira FLM, Benetton MLFN, Carneiro M (2008) The prevalence of malnutrition and its risk factors in children attending outpatient clinics in the city of Manaus, Amazonas, Brazil. Archlatinoamnutr 58(3):234-240

13. Herrador Z, Sordo L, Gadisa E et al (2014) Cross-Sectional study of malnutrition and associated factors among school aged children in rural and urban settings of Fogera and LiboKemkem Districts, Ethiopia. PLoS One 9(9):e105880. https://doi.org/10.1371/journal.pone.0105880

14. Ahmed N, Barnett I, Longhurst R (2015) Determinants of child undernutrition in Bangladesh literature review, produced by MQSUN consortium partner, The Institute of Development Studies (IDS)

15. Abdelaziz SB, Youssef MRL, Sedrak AS, Labib JR (2015) Nutritional status and dietary habits of school children in Beni-Suef Governorate, Egypt. Food Nutr Sci 6:54-63

16. Mesfin F, Berhane Y, Worku A (2015) Prevalence and associated factors of stunting among primary school children in Eastern Ethiopia. Nutr Diet Suppl 7:61-68

17. Yeasmin S, Islam K (2016) Prevalence and determinants of undernutrition among school age slum children in Dhaka city, Bangladesh. J Nutr Health Sci 3(2):201. https://doi.org/10.15744/2393-9060.3.201

18. National family health survey (NFHS-4) 2012-14. Mumbai: International Institute for Population Sciences (IIPS) and Macro International; 2009. Available from: http://www.rchiips.org/nfhs/nfhs4.shtml

19. Raban MZ, Dandona R, Dandona L (2009) Essential health information available for India in the public domain on the internet. BMC Public Health 9(1):208

20. Das M, Mandal GC, Ray S (2014) Prevalence of undernutrition among children aged 5-10 years of North-24 Parganas District, West Bengal, India Ind. J Phys Anthrop Hum Genet 33(1):91-97

21. Kumar BPR, Dudala SR, Rao AR (2013) Kuppuswamy's Socio-economic status scale - a revision of economic parameter for 2012. Int J Res DevHealth 1(1):2-4

22. World Health Organization (2007) Growth reference data for 5-19 years. WHO, Geneva

23. WHO Expert Committee on Physical Status (1995) Physical status: the use and interpretation of anthropometry, report of a WHO expert committee. World Health Organization (WHO Technical Report Series, No. 854), Geneva

24. Chakrabarty S, Bharati P (2010) Nutritional status among the Shabar tribal children living in urban, rural and forest habitats of Orissa, India. Ital J Publ Health 7(3):303-310

25. Meshram II, Arlappa N, Balakrishna N et al (2012) Prevalence and determinants of undernutrition and its trends among preschool tribal children of Maharashtra state, India. J Trop Pediatr 58(2):125-132

26. Tigga PL, Mondal N, Sen J (2015) Effects of certain socio-economic, sociodemographic and life style factors on the prevalence of thinness among pre-school children of North Bengal, India. Epidemiol Biostat Publ. Health 12(1):e10282-1-11 
27. Lucovnik M, Starc G, Golja P, Verdenik I, StucinGantar I (2018) Effects of perinatal factors on body mass index and physical fitness of school-age children. ZdrVarst. 57(2):81-87

28. Meshram II, Mallikharjun Rao K, Reddy CG et al (2016) Prevalence of under nutrition and its predictors among under 5 year children in Surat region, Gujarat, India. J Clin Nutr Diet 2:1

29. Sapkota VP, Gurung CK (2009) Prevalence and predictors of underweight, stunting and wasting in under-five children. Nepal Health Res Counc 7:120-126

30. Kanungo S, Bhowmik K, Mahapatra T, Mahapatra S, Bhadra UK, Sarkar K (2015) Perceived morbidity, health care-seeking behavior and their determinants in a poor-resource setting: observation from India. PLoS One 10(5):e0125865. https://doi.org/10.1371/journal.pone.0125865

31. Ramamurthy T, Yamasaki S, Takeda Y, Nair GB (2003) 15. Vibrio cholerae O139 Bengal: odyssey of a fortuitous variant. Microbes Infect 5:329-344

32. Pal A, De S, Sengupta P, Maity P, Dhara PC (2014) An investigation on prevalence of anemia in relation to BMI and nutrient intake among adult rural population of West Bengal, India. Epidemiol Biostat Public Health 11(2):e89151-e891510

\section{Publisher's Note}

Springer Nature remains neutral with regard to jurisdictional claims in published maps and institutional affiliations.

\section{Submit your manuscript to a SpringerOpen ${ }^{\odot}$ journal and benefit from:}

- Convenient online submission

- Rigorous peer review

- Open access: articles freely available online

- High visibility within the field

- Retaining the copyright to your article

Submit your next manuscript at $\boldsymbol{\nabla}$ springeropen.com 